\title{
REDUCING RENEWABLE RESOURCE DEMAND FLUCTUATION USING SOFT PRECEDENCE RELATIONS IN PROJECT SCHEDULING
}

\author{
Piotr JASKOWSKI* (D), Slawomir BIRUK ${ }^{(i)}$ \\ Department of Construction Management and Methods, Faculty of Civil Engineering and Architecture, \\ Lublin University of Technology, Lublin, Poland
}

Received 04 March 2018; accepted 22 May 2018

\begin{abstract}
Renewable resource levelling is the core of the scheduling process. A perfect schedule ensures that resource supply corresponds to the demand at every unit of project time. A classic approach to resource levelling in schedules with predefined project completion dates consists in manipulating processes start dates. Resource deployment can be also improved by considering alternative construction processes execution modes with various crew formations, and by allowing activities to be split. There are other possibilities: in many practical cases, the activities' precedence logic predefined in the network model can be changed with no harm to the project outcome. Within the structure of the project network model, some precedence relations between activities would definitely be of fixed (hard) character, whereas some might allow the activities to be executed at the same time or arranged in a variety of logical sequences. The authors use soft precedence relations that let the processes run in reversed order or that can be cancelled, in search for improved resource usage profiles. The benefits of scheduling with soft precedence relations are demonstrated by an example.
\end{abstract}

Keywords: construction project management, project scheduling, renewable resource levelling, resource utilization, soft logic, schedule optimization.

\section{Introduction}

Economic allocation of renewable resources is one of the most difficult tasks of the scheduler. Construction projects that include unrepeatable processes are usually scheduled by means of network methods. One of the most popular network-based methods is the Critical Path Method. It enables the user to prepare schedules of the shortest completion time, to determine critical processes, and to calculate floats of non-critical processes. However, this method has some drawbacks: it does not directly provide tools for resource availability analysis and solving availability conflicts - it is based on the assumptions that the first thing is to schedule the tasks, and the resources are going to be matched with the schedule later, as if they were initially considered unlimited.

The methods of finding optimal or suboptimal plans that account for actual limitations of resource availability, or providing better use of resources at hand, are the object of research for decades. Resource allocation and levelling problems belong to the favorite themes of theoretical analyses based on optimization methods developed in operations research studies. Usually, their main aim is to reduce duration of projects with renewable resource availability constraints, to minimize resource demand fluctuation, and to minimize resource cost while meeting project deadlines.

In the case of perfect renewable resource allocation, the demand for resources would match their supply each day of the project. Assuming that the availability limit of a particular resource is constant during the construction period, the resource usage profile (a diagram presenting the number of employed resource units against time) should be rectangular. In construction projects, the resources usage profiles are not uniform - usually have some peaks and valleys. If small, they can be compensated by assigning other resources that are less busy at the moment, to tasks initially not meant for them. However, it is important to aim for levelled general employment (all trades) and thereby to minimize daily demand. In the case of machine use, unlevelled usage is a source of financial loss due to underutilization of machines.

${ }^{\star}$ Corresponding author. E-mail: p.jaskowski@pollub.pl 
Rational use of resources in a project means economic efficiency. It simplifies resource management across the whole construction enterprise. Unlevelled resources usage profile usually implies that the resources need to be transferred from site to site, which adds no value and generates costs. Among others, it increases cost of construction site welfare facilities that need to be expanded in the employment peak periods and reduced or left underutilized in the time of lower demand for resources.

In the mathematical models of resources levelling problems presented in the literature on the subject, the authors define various objective functions, for instance: minimizing the peak resource demand within a determined period (day, week etc.) (Wagner et al. 1964), minimizing the sum of the square of the deviations between resource usage for a unit time (day, week etc.) and the average resource usage or the sum of the absolute deviations in resource usage in consecutive time units (Easa 1989), minimizing the moment of the resource histogram around the time axis (Harris 1990), and minimizing the maximum absolute deviation between resource usage for a time unit and the average resource usage (Senouci et al. 2004). To select the best objective function, one should consider preferences of the decision-maker (Mattila, Abraham 1998).

Shao and Liu (2015) criticized the existing measures of resource utilization quality and argued that this quality may be measured by the cost of resources' idle time and mobilization caused by resource imbalance. Christodoulou et al. (2010) applied the entropy-maximization approach for solving resource levelling problem: the entropy function assumes greater values if all prior values are of equal probability. They claim that this method is superior to the approach using minimum moment method.

The methods applied to scheduling construction projects with resource optimization can be roughly divided into three groups:

- searching for exact optimal solutions using integer or binary programming (Easa 1989; Rieck et al. 2012), branch and bound technique (Gather et al. 2011), and dynamic programming (Bandelloni et al. 1994);

- searching for suboptimal solutions using heuristic algorithms (Ballestín et al. 2007; He, Zhang 2013) and methaheuristics, for example: tabu search (Koulinas, Anagnostopoulos 2013), particle swarm (Zhang et al. 2006), simulated annealing (Anagnostopoulos, Koulinas 2010), ant colony (Geng et al. 2011), genetic and evolutionary algorithms (Kaiafa, Chassiakos 2015; Chan et al. 1996; Leu, Yang 1999; Ponz-Tienda et al. 2013);

- using expert systems (Leu et al. 2000) with neural networks (Savin et al. 1996) and fuzzy logic (Iyer et al. 2015).

Reduction of the employment level and resource levelling is generally achieved by changing organization of the works by shifting processes' start dates within the existing floats. Resource utilization can be also improved by selecting different construction methods - considering options (process modes) of lower resource demand and longer duration. Karaa and Nasr (1986) noted that it may reason- able to interrupt some processes and allocate resources released this way to other processes. This can seriously improve resource usage profile levelling. This approach, mathematically formalized in different ways, was applied, among others, by Mattila and Abraham (1998), Son and Skibniewski (1999), Son and Mattila (2004), and Hariga and El-Sayegh (2011). Another way to improve utilization of the contractor's own plant and workforce are subcontracting and partnering. The problem of subcontracting works under limited availability of the general contractor's renewable resources was analyzed, among others, by Jaskowski (2008), whereas the benefits of partnering and criteria of partner selection were discussed by Radziszewska-Zielina (2010).

To reduce peaks and valleys in resource demand, Benjaoran et al. (2015) introduced the concept of selecting optimal relationship options (types) between project activities. They state that an activity of the project network may be linked with other activities in a number of ways while staying in accordance with the project logic. Selecting the alternative type of relation may affect the activity's float and change the project's resource demand patterns.

Some authors (Jaskowski, Sobotka 2012; Tamimi, Diekmann 1988) observed that using soft precedence relationships between processes in the project network could improve schedule flexibility by reducing project duration and increasing total floats of project activities. The precedence links between construction processes represent space, construction methods, project logic limitations, but may be also the result of availability of resources. They may be of mandatory or discretionary character. The constraints expressed by mandatory dependencies are called hard-logic: they are agreed in the contract or determined by the nature of the tasks themselves (for instance, a slab on grade must be started after, and not before, trimming the bottom of the excavation that accommodates it, and this sequence cannot be changed). Discretionary dependencies (also known as soft logic) are defined by the project manager on the basis of their own experience or the best practices. Recognizing the soft and hard relationships in a schedule offers more possibilities to the planner in the search for best sequence of processes: it may occur possible to schedule processes' start times later with no detriment to the completion time, and improving resource utilization profile.

In this paper, the authors consider the effects of introducing soft relations that enable the processes to be executed concurrently or in reversed order. This is done in search for improved resource usage. An example is provided to illustrate the analysis and provide a better insight into the proposed method.

\section{Mathematical formulation of the resources levelling problem in project networks with soft logic}

A construction project is broken down into activities (construction processes) connected by precedence 
relations and modelled as activity on node network with a single dummy start and a single end node. The relations, arising from the logic of construction methods and organizational constraints, are defined for pairs of activities. Thus, a graph $G=\langle V, E\rangle$, represents the project network, where $V=\{1,2, \ldots, n\}$ is a set of activities, and $E \subset V \times V$ stands for the set of relations. Duration $t_{i}$ is estimated for each activity $i \in V$.

The relation set $E$ is divided into two separate subsets: one of them $(H)$ comprises hard relations, the other $(S)$ - soft relations. The hard relations are of finishto-start type. The set of soft relations is further divided into two subsets: $S R$ with REVERSED-type links and SC with CANCELED-type links. $S R$ and $S C$ types of relations were closer described in Jaskowski and Sobotka (2012). The REVERSED-type relations allow the activities to be executed in reversed order, whereas CANCELLED-type ones allow the activities to run in parallel assuming that additional resources are allotted to them. The latter is intended to be used for pairs of processes scheduled in sequence only for the reason of limited resources. The authors assume that soft relations are not used to link dummy start and end nodes with other processes.

Weakening the relations of REVERSED or CANCELEDtype means that the relations are changed compared with their initial form in the baseline network. This may, in some cases, cause extra work. For instance, wiring for a building's electrical system is typically done before wet plastering. A reversed order of these processes is possible (thus, wiring and wet plastering can be connected by REVERSED-type relation, if the planner considers changing their sequence), but it involves damaging plasters, so extra repairs of their surface need to be done, taking time (and money). However, if changing the sequence of processes is to be achieved only by means of changing the crew's routes from one location to the other, this process does not affect process duration and is not connected with any additional work. Weakening the links between the processes connected with CANCELED-type relations, if achieved by employing extra resources, may change their duration.

Let $d_{l}^{(i, j)}$ is the duration of extra works, caused by weakening a soft relation between processes $i$ and $j$, $(i, j) \in S$. The increase of duration $d_{l}^{(i, j)}$ concerns only specific processes $l \in V$. The remaining values of $d_{l}^{(i, j)}$ (for remaining, not affected processes) equal 0.
Each project activity (apart from the first and the last dummy node) should have at least one predecessor and one successor, even if a soft link was to be weakened. In some cases, additional relations need to be introduced into the project network to fulfil the condition (Jaskowski, Sobotka 2012).

For any pair of processes $(i, j) \in S R$ and $(i, j) \in S C$, variables $y_{i, j} \in\{0,1\}$ and $z_{i, j} \in\{0,1\}$, respectively, are introduced. They allow the user to model the decision to weaken or not to weaken the relation for soft relations. These variables assume values of 0 , when process $j$ cannot start before process $i$ has been executed. When $y_{i, j}=1$, process $j$ will finish before the start of process $i$ (the processes are allowed to run in reversed order), and for $z_{i, j}=1$, process $j$ is allowed to start before the completion of $i$ (cancellation of the link).

Each process $i \in V$ engages a constant number $z_{i, r}$ of resource units of certain types $r$; the types belong to a set of resource types $(r \in R)$.

Additionally, the following notations are introduced: $Z_{r, t}-$ a value of daily demand for a resource $r \in R$ on day $t(t=1,2, \ldots, T), x_{i, t}-$ a binary variable that assumes the value of 1 if the process $i \in V$ is carried out on day $t$, and equals 0 - otherwise.

Let us assume that the planner wants to define the processes' start dates $s_{j}, \forall j \in V$, in a way that makes the project duration no longer than the imposed duration (or date) $T$, and that the total of each resource type usage maxima is minimal.

The mathematical model is presented in Table 1. It comprises the objective function, constraints and boundary conditions described by linear analytic relationships.

Conditions (13) and (14) were introduced for calculating project activity start dates, and for introducing the binary variables $x_{i, t}$, to enable calculation of the daily demand for resources.

\section{Example}

To illustrate the merits of incorporating soft logic in project networks in improving resource utilization, let us consider a simple example of a project composed of twelve processes. The project network is presented in Figure 1. Other input is summarized in Table 2.

Each process engages only one and the same type of resource. The imposed project duration is 10 days. One

Table 1. Mathematical model

\begin{tabular}{|l|c|l|}
\hline \multicolumn{1}{|c|}{ Formula } & No. & \multicolumn{1}{|c|}{ Application / function } \\
\hline Objective function: & (1) & Minimizing the sum of maximal daily usage of each resource type \\
\hline $\min z: z=\sum_{r \in R} \alpha_{r}$ & (2) & $\begin{array}{l}\text { Daily usage of } r \text {-type resource cannot exceed its maximal value (variable } \alpha_{r} \text { is minimized } \\
\text { in the objective function, so it expresses the maximal daily usage of } r \text {-type resource) }\end{array}$ \\
\hline Constraints: &
\end{tabular}


End of Table 1

\begin{tabular}{|c|c|c|}
\hline Formula & No. & Application / function \\
\hline $\begin{array}{l}D_{i}=t_{i}+\sum_{(k, l) \in S R} d_{i}^{(k, l)} y_{k, l} \\
+\sum_{(k, l) \in S C} d_{i}^{(k, l)} z_{k, l}, \quad \forall i \in V\end{array}$ & $(3)$ & $\begin{array}{l}\text { Auxiliary formula to calculate processes durations taking into account additional works } \\
\text { caused by weakening soft relations }\end{array}$ \\
\hline$s_{1}=0$ & $(4)$ & The first process starts at moment 0 \\
\hline $\begin{array}{l}s_{j} \geq s_{i}+D_{i} \\
\forall(i, j) \in H\end{array}$ & $(5)$ & $\begin{array}{l}\text { If processes } i \text { and } j \text { are connected with hard relation, successor } j \text { cannot start before its } \\
\text { predecessor's } i \text { finish }\end{array}$ \\
\hline $\begin{array}{l}C y_{i, j}+s_{j} \geq s_{i}+D_{i} \\
\forall(i, j) \in S R\end{array}$ & $(6)$ & $\begin{array}{l}\text { Formula to calculate start dates of processes connected with REVERSED-type relations. } \\
\text { If the relation between processes } i \text { and } j \text { is weakened }\left(y_{i, j}=1\right) \text {, the constraint is always } \\
\text { fulfilled ( } C \text { is a sufficiently large number). Otherwise, process } j \text { starts after process } i \text { is } \\
\text { finished }\end{array}$ \\
\hline $\begin{array}{l}C z_{i, j}+s_{j} \geq s_{i}+D_{i} \\
\forall(i, j) \in S C\end{array}$ & $(7)$ & $\begin{array}{l}\text { Formula to calculate start dates of processes connected with CANCELED-type links. If the } \\
\text { relation between processes } i \text { and } j \text { is weakened }\left(z_{i, j}=1\right) \text {, the constraint is always fulfilled. } \\
\text { Otherwise, process } j \text { starts after process } i \text { is finished }\end{array}$ \\
\hline $\begin{array}{l}s_{j}+D_{j} \leq s_{i}+C\left(1-y_{i, j}\right) \\
\forall(i, j) \in S R\end{array}$ & $(8)$ & $\begin{array}{l}\text { Formula to calculate start dates of processes connected with REVERSED-type links. If the } \\
\text { relation between processes } i \text { and } j \text { is weakened }\left(y_{i, j}=1\right) \text {, process } i \text { starts after process } j \text { is } \\
\text { finished. Otherwise, the constraint is always fulfilled }\end{array}$ \\
\hline $\begin{array}{l}s_{j} \leq s_{i}+D_{i}+C\left(1-z_{i, j}\right) \\
\forall(i, j) \in S C\end{array}$ & $(9)$ & $\begin{array}{l}\text { Formula to calculate start dates of processes connected with CANCELED-type links. If the } \\
\text { relation between processes } i \text { and } j \text { is weakened }\left(z_{i, j}=1\right) \text {, process } j \text { starts before process } j \text { is } \\
\text { finished. Otherwise, the constraint is always fulfilled }\end{array}$ \\
\hline$s_{n}+D_{n} \leq T$ & $(10)$ & The finish date of the last activity in the project network can't exceed the contractual date \\
\hline$\sum_{t=1}^{T} x_{i, t}=D_{i}, \forall i \in V$ & $(11)$ & The sum of an process realization days equals its duration \\
\hline $\begin{array}{l}Z_{r, t}=\sum_{i \in V} z_{i, r} \cdot x_{i, t}, \\
\forall r \in R, \forall t \in[1, T]\end{array}$ & $(12)$ & Calculation of daily resource demand \\
\hline $\begin{array}{l}s_{i}+D_{i} \geq t \cdot x_{i, t}, \\
\forall i \in V, \forall t \in[1, T]\end{array}$ & $(13)$ & Each process' finish date is calculated as the last day when it is performed \\
\hline $\begin{array}{l}T-s_{i} \geq(T-t+1) \cdot x_{i, t} \\
\forall i \in V, \forall t \in[1, T]\end{array}$ & $(14)$ & Each process start date is calculated as the first day when it is performed \\
\hline \multicolumn{3}{|l|}{ Boundary conditions: } \\
\hline$s_{i} \geq 0, \quad \forall i \in V$ & $(15)$ & Processes' start dates can take only non-negative values \\
\hline $\begin{array}{l}x_{i, t} \in\{0,1\}, \\
\forall i \in V, \forall t \in[1, T]\end{array}$ & $(16)$ & Process $i$ is either executed on day $t$ or not \\
\hline $\begin{array}{l}y_{i, j} \in\{0,1\} \\
\forall(i, j) \in S R\end{array}$ & (17) & REVERSED-type relation between processes $i$ and $j$ is either weakened or not \\
\hline $\begin{array}{l}z_{i . j} \in\{0,1\} \\
\forall(i, j) \in S C\end{array}$ & (18) & CANCELED-type relation between processes $i$ and $j$ is either weakened or not \\
\hline
\end{tabular}




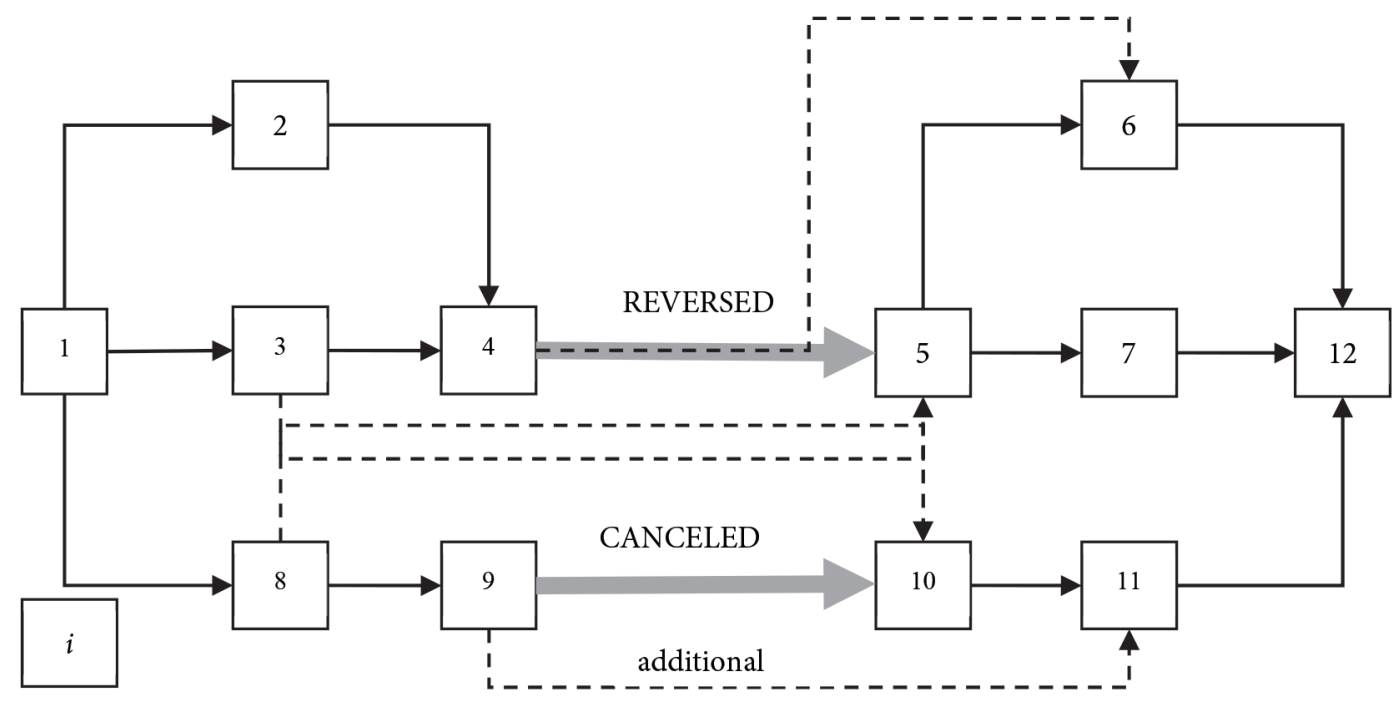

Figure 1. Project network

Table 2. Input data

\begin{tabular}{|c|c|c|}
\hline $\begin{array}{c}\text { Process number } \\
i\end{array}$ & $\begin{array}{c}\text { Process duration } \\
t_{i} \text { [days] }\end{array}$ & $\begin{array}{c}\text { Resource demand } \\
r_{i, 1} \text { [units] }\end{array}$ \\
\hline 1 & 0 & 0 \\
\hline 2 & 3 & 4 \\
\hline 3 & 1 & 4 \\
\hline 4 & 2 & 2 \\
\hline 5 & 2 & 2 \\
\hline 6 & 3 & 4 \\
\hline 7 & 2 & 2 \\
\hline 8 & 1 & 1 \\
\hline 9 & 3 & 2 \\
\hline 10 & 1 & 1 \\
\hline 11 & 2 & 1 \\
\hline 12 & 0 & 0 \\
\hline
\end{tabular}

REVERSED-type relation connects processes 4 and 5. One CANCELED-type relation connects processes 9 and 10 . Weakening the latter results in the process 10 duration being increased by 1 day.

The mathematical model of the issue in the example was solved using Lingo 14.0. Figure 2 shows the project schedule and the optimal resource utilization profile assuming that the two soft precedence relations cannot be weakened $\left(y_{4,5}=z_{9,10}=0\right)$. Figure 3 shows the project schedule and resource utilization profile for the optimal solution assuming the possibility of weakening the soft precedence relations. In the latter case, both soft relations have been weakened, and the maximum demand for the resource has been reduced from 8 to 6 units, which contributed to the elimination of peaks and valleys. This excludes the beginning and finishing stages of the project, where the employment figures naturally rise and drop).
Table 3 summarizes the input and the results of 10 experiments: all used the same network structure, but differed in process durations.

In most cases (90\%) the maximum resource demand was lower when weakening the soft precedence relations was allowed.

Table 3. Input and the results of 10 experiments

\begin{tabular}{|c|c|c|c|c|c|c|c|c|c|c|}
\hline \multirow{2}{*}{$\begin{array}{c}\text { Process number } \\
i\end{array}$} & \multicolumn{10}{|c|}{$\begin{array}{c}\text { Process duration } \\
\left.t_{i} \text { [days }\right] \\
\end{array}$} \\
\hline & 1 & 2 & 3 & 4 & 5 & 6 & 7 & 8 & 9 & 10 \\
\hline 1 & 0 & 0 & 0 & 0 & 0 & 0 & 0 & 0 & 0 & 0 \\
\hline 2 & 3 & 2 & 3 & 2 & 1 & 3 & 1 & 3 & 2 & 1 \\
\hline 3 & 3 & 2 & 1 & 2 & 2 & 3 & 1 & 2 & 3 & 2 \\
\hline 4 & 2 & 1 & 2 & 3 & 2 & 2 & 3 & 1 & 1 & 2 \\
\hline 5 & 1 & 2 & 3 & 1 & 2 & 2 & 3 & 2 & 1 & 3 \\
\hline 6 & 1 & 2 & 1 & 3 & 2 & 1 & 3 & 3 & 2 & 3 \\
\hline 7 & 3 & 3 & 2 & 2 & 3 & 3 & 1 & 3 & 3 & 2 \\
\hline 8 & 1 & 1 & 3 & 1 & 2 & 1 & 2 & 2 & 1 & 3 \\
\hline 9 & 2 & 2 & 1 & 1 & 2 & 3 & 2 & 3 & 2 & 1 \\
\hline 10 & 1 & 3 & 2 & 2 & 2 & 1 & 3 & 1 & 3 & 3 \\
\hline 11 & 2 & 2 & 3 & 3 & 1 & 3 & 3 & 2 & 3 & 1 \\
\hline 12 & 0 & 0 & 0 & 0 & 0 & 0 & 0 & 0 & 0 & 0 \\
\hline $\begin{array}{l}\text { maximum } \\
\text { demand for } \\
\text { the resource } \\
\text { (weakening } \\
\text { soft precedence } \\
\text { relation not } \\
\text { allowed) }\end{array}$ & 8 & 6 & 8 & 8 & 6 & 9 & 9 & 8 & 7 & 8 \\
\hline $\begin{array}{l}\text { maximum } \\
\text { demand for } \\
\text { the resource } \\
\text { (weakening } \\
\text { soft precedence } \\
\text { relation } \\
\text { permitted) }\end{array}$ & 6 & 6 & 5 & 6 & 5 & 6 & 6 & 7 & 6 & 6 \\
\hline
\end{tabular}




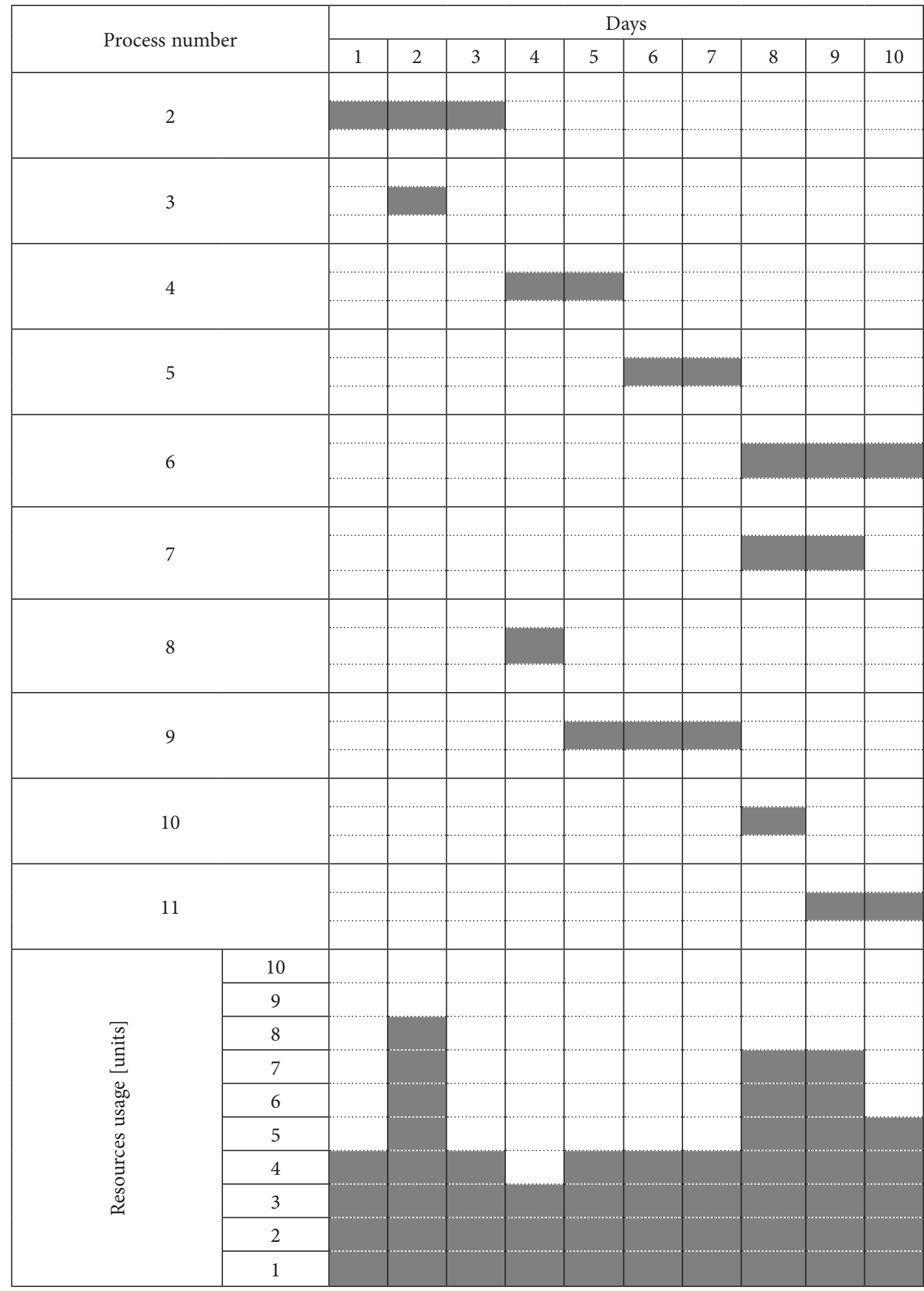

Figure 2. Project schedule and the optimal resource utilization profile (weakening soft precedence relation not allowed) 


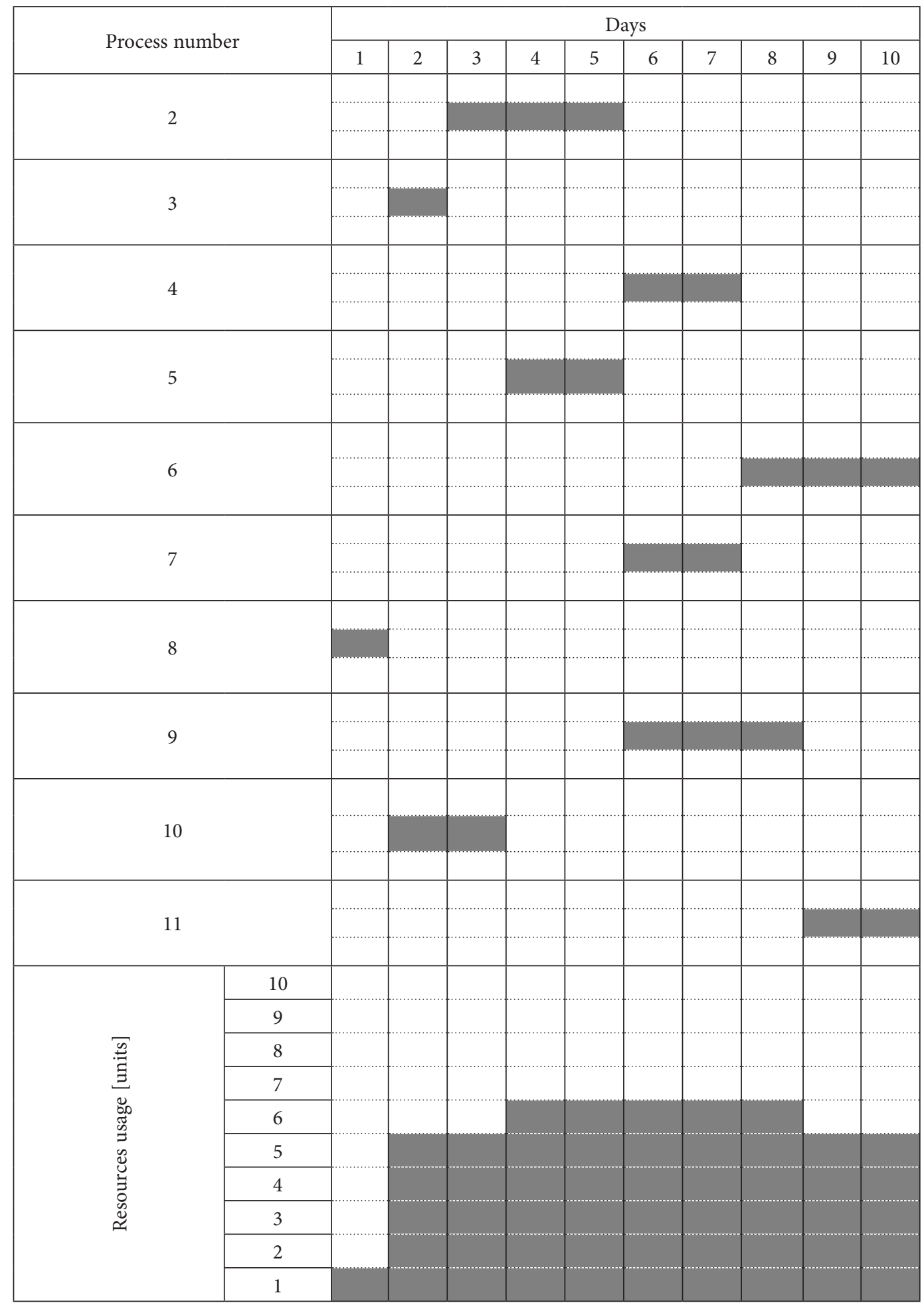

Figure 3. Project schedule and resource utilization profile for the optimal solution (weakening soft precedence relation permitted) 


\section{Conclusions}

Rational use of resources has a profound impact on economic efficiency of the project as well as helps manage workforce and plant in the whole construction company. If the resource demand is levelled, the contractor is able to make full use of their capacity.

Moreover, the resource levelling problem can be considered from the point of optimizing the projects' and the contractor organization's logistic flows. Unlevelled resources imply that it is necessary to frequently move the plant and workforce from one project to the other, or employing external resources for a short time - this generates expenditures that could be avoided. The construction site welfare facilities are typically designed according to peak employment figures - if the number of workers strongly fluctuates, these facilities cannot be fully used, what adds to the project cost.

Resource usage efficiency is one of the main objectives of optimization of construction projects schedules. Most of the existing research focuses on the problem-solving methodology or choosing the appropriate performance metrics in optimization models while paying little attention to the precedence relations modelling and flexibility. Introducing soft precedence relations into project network models allows the planner to find a schedule with better resource usage. The applicability of soft precedence relations in constructing project networks is naturally case-specific. Before they are introduced into the analysis, the extra cost of additional works (if any) should be considered. Nevertheless, using them may yield reduced project durations this was confirmed, among others, by Jaskowski and Sobotka (2012) and Tamimi and Diekmann (1988). Thanks to them, the project activities may have greater total floats, so their start times can be scheduled more flexibly with no danger to the contractual project due date. This enables the planner to find a better resource utilization profile; this profile is never worse than the one created without weakening the soft relations. This was confirmed by the results of the example.

The problem of resource levelling analyzed in the paper is modelled in the form of a linear mixed integer / binary program. To efficiently solve large-size problems, the problem solving process needs to be supported with computer technology. Heuristic or metaheuristic algorithms can be applied to reduce computational effort, and it would be advisable to develop dedicated software (computer systems) to solve complex practical problems. Introducing soft precedence relations in the project model is only one of many ways improving resource utilization and levelling. Combination of all of them will help create the computer decision making support system in the project resource management area.

\section{Acknowledgement}

The authors gratefully acknowledge the financial support by the Ministry of Science and Higher Education in Poland $(S / 63 / 2018)$.

\section{Notations}

\section{Symbols:}

G - graph modelling project scope and precedence relations between processes;

$V-\quad$ set of project processes;

$E-\quad$ set of network edges (precedence relations between processes);

$H$ - subset of hard precedence relations;

$S$ - $\quad$ subset of soft precedence relations;

$S R$ - subset of REVERSED-type precedence relations;

$S C$ - subset of CANCELED-type precedence relations;

$R-\quad$ set of resources types;

$r$ - type of renewable resource;

$i, j, l$ - process number;

$t$ - day number.

\section{Model's parameters:}

$z_{i, r}$ - resource $r$-type demand for process $i$;

$t_{i}-$ estimated duration of process $i$;

$d_{l}^{(i, j)}$ - increase of duration of process $l$ caused by weakening a particular relation between processes $i$ and $j$;

$T$ - completion date (predefined, e.g. contractual);

$C$ - a sufficiently large constant.

\section{Model's variables:}

$y_{i, j}$ - binary variable modelling decision to weak the REVERSED-type relation;

$z_{i, j}$ - binary variable modelling decision to weak the CANCELED-type relation;

$s_{i}-\quad$ start date of process $i$;

$x_{i, t}-$ binary variable modelling execution of process $i$ on day $t$;

$a_{r}-$ maximal demand for resource $r$-type during the whole period of the project;

$D_{i}-$ duration of a process $i$ that includes additional work and increase of duration due to weakening soft relations;

$Z_{r, t}$ - daily demand for resource $r$-type on day $t$.

\section{References}

Anagnostopoulos, K. P.; Koulinas, G. K. 2010. A simulated annealing hyperheuristic for construction resource levelling, Construction Management and Economics 28(2): 163-175. https://doi.org/10.1080/01446190903369907

Ballestín, F.; Schwindt, C.; Zimmermann, J. 2007. Resource leveling in make-to-order production: modeling and heuristic solution method, International Journal of Operations Research 4(1): 50-62.

Bandelloni, M.; Tucci, M.; Rinaldi, R. 1994. Optimal resource leveling using non-serial dynamic programming, European Journal of Operational Research 78(2): 162-177. https://doi.org/10.1016/0377-2217(94)90380-8

Benjaoran, V.; Tabyang, W.; Sooksil, N. 2015. Precedence relationship options for the resource levelling problem using a genetic algorithm, Construction Management and Economics 33(9): 711-723. https://doi.org/10.1080/01446193.2015.1100317 
Chan, W.-T.; Chua, D. K. H.; Kannan, G. 1996. Construction resource scheduling with genetic algorithms, Journal of Construction Engineering and Management 122: 125-132. https://doi.org/10.1061/(ASCE)0733-9364(1996)122:2(125)

Christodoulou, S. E.; Ellinas, G.; Michaelidou-Kamenou, A. 2010. Minimum moment method for resource leveling using entropy maximization, Journal of Construction Engineering and Management 136(5): 518-527. https://doi.org/10.1061/(ASCE)CO.1943-7862.0000149

Easa, S. M. 1989. Resource leveling in construction by optimization, Journal of Construction Engineering and Management 115(2): 302-316. https://doi.org/10.1061/(ASCE)0733-9364(1989)115:2(302)

Gather, T.; Zimmermann, J.; Bartels, J. H. 2011. Exact methods for the resource levelling problem, Journal of Scheduling 14(6): 557-569. https://doi.org/10.1007/s10951-010-0207-8

Geng, J. Q.; Weng, L. P.; Liu, S. H. 2011. An improved ant colony optimization algorithm for nonlinear resource-leveling problems, Computers \& Mathematics with Applications 61(8): 2300-2305. https://doi.org/10.1016/j.camwa.2010.09.058

Hariga, M.; El-Sayegh, S. M. 2011. Cost optimization model for the multiresource leveling problem with allowed activity splitting, Journal of Construction Engineering and Management 137(1): 56-64. https://doi.org/10.1061/(ASCE)CO.1943-7862.0000251

Harris, B. R. B. 1990. Packing method for resource leveling (Pack), Journal of Construction Engineering and Management 116(2): 331-350. https://doi.org/10.1061/(ASCE)0733-9364(1990)116:2(331)

He, L.; Zhang, L. 2013. Dynamic priority rule-based forwardbackward heuristic algorithm for resource levelling problem in construction project, Journal of the Operational Research Society 64(8): 1106-1117. https://doi.org/10.1057/jors.2013.33

Iyer, P.; Liu, Y.; Sadeghpour, F.; Brennan, R. W. 2015. A fuzzylogic based resource levelling optimisation tool, IFAC-PapersOnLine 28: 1942-1947. https://doi.org/10.1016/j.ifacol.2015.06.371

Jaskowski, P. 2008. Designing the structure of a construction project operating system using evolutionary algorithm, Archives of Civil Engineering 54(2): 371-394.

Jaskowski, P.; Sobotka, A. 2012. Using soft precedence relations for reduction of the construction project duration, Technological and Economic Development of Economy 18(2): 262-279. https://doi.org/10.3846/20294913.2012.666217

Kaiafa, S.; Chassiakos, A. P. 2015. A genetic algorithm for optimal resource-driven project scheduling, Procedia Engineering 123: 260-267. https://doi.org/10.1016/j.proeng.2015.10.087

Karaa, F. A.; Nasr, A. Y. 1986. Resource management in construction, Journal of Construction Engineering and Management 112(3): 346-357. https://doi.org/10.1061/(ASCE)0733-9364(1986)112:3(346)

Koulinas, G. K.; Anagnostopoulos, K. P. 2013. A new tabu search-based hyper-heuristic algorithm for solving construction leveling problems with limited resource availabilities, Automation in Construction 31: 169-175. https://doi.org/10.1016/j.autcon.2012.11.002

Leu, B. S.; Yang, C. 1999. GA-based multicriteria optimal for construction scheduling, Journal of Construction Engineering and Management 125: 420-427. https://doi.org/10.1061/(ASCE)0733-9364(1999)125:6(420)

Leu, S. S.; Yang, C. H.; Huang, J. C. 2000. Resource leveling in construction by genetic algorithm-based optimization and its decision support system application, Automation in Construction 10(1): 27-41. https://doi.org/10.1080/01446193.2015.1100317
Mattila, K. G.; Abraham, D. M. 1998. Resource leveling of linear schedules using integer linear programming, Journal of Construction Engineering and Management 124(3): 232-244. https://doi.org/10.1061/(ASCE)0733-9364(1998)124:3(232)

Ponz-Tienda, J. L.; Yepes, V.; Pellicer, E.; Moreno-Flores, J. 2013. The resource leveling problem with multiple resources using an adaptive genetic algorithm, Automation in Construction 29: 161-172. https://doi.org/10.1016/j.autcon.2012.10.003

Radziszewska-Zielina, E. 2010. Analysis of the impact of the level of partnering relations on the selected indexes of success of Polish construction enterprises, Inzinerine Ekonomika Engineering Economics 21(3): 324-335.

Rieck, J.; Zimmermann, J.; Gather, T. 2012. Mixed-integer linear programming for resource leveling problems, European Journal of Operational Research 221(1): 27-37. https://doi.org/10.1016/j.ejor.2012.03.003

Savin, D.; Alkass, S.; Fazio, P. 1996. Construction resource leveling using neural networks, Canadian Journal of Civil Engineering 23(4): 917-925. https://doi.org/10.1139/196-898

Senouci, A. B.; Eldin, N. N.; Asce, M. 2004. Use of genetic algorithms in resource scheduling of construction projects, Journal of Construction Engineering and Management 130(6): 869-877. https://doi.org/10.1061/(ASCE)0733-9364(2004)130:6(869)

Shao, M.; Liu, X. 2015. Control indicators for resource leveling in project network planning, in Proceedings of the 2015 International Conference on Applied Science and Engineering Innovation, 1097-2002. https://doi.org/10.2991/asei-15.2015.217

Son, J.; Mattila, K. G. 2004. Binary resource leveling model: activity splitting allowed, Journal of Construction Engineering and Management 130(6): 887-894. https://doi.org/10.1061/(ASCE)0733-9364(2004)130:6(887)

Son, J.; Skibniewski, M. J. 1999. Multiheuristic approach for resource leveling problem in construction engineering: hybrid approach, Journal of Construction Engineering and Management 125: 23-31. https://doi.org/10.1061/(ASCE)0733-9364(1999)125:1(23)

Tamimi, S.; Diekmann, J. 1988. Soft logic in network analysis, Journal of Computing in Civil Engineering 2(3): 289-300. https://doi.org/10.1061/(ASCE)0887-3801(1988)2:3(289)

Wagner, H. M.; Giglio, R. J.; Glaser, R. G. 1964. Preventive maintenance scheduling by mathematical programming, Management Science 10(2): 316-334. https://doi.org/10.1287/mnsc.10.2.316

Zhang, H.; Li, H.; Tam, C. M. 2006. Particle swarm optimization for resource-constrained project scheduling, International Journal of Project Management 24(1): 83-92. https://doi.org/10.1016/j.ijproman.2005.06.006 